\title{
A Novel Assay for Determining Bleeding Risk in Factor XI Deficiency
}

\author{
Paula H.B. Bolton-Maggs ${ }^{10}$ \\ ${ }^{1}$ Faculty of Biology, Medicine and Health, The University of \\ Manchester, Manchester, United Kingdom
}

Thromb Haemost 2021;121:121.

Factor XI (FXI) plays a modulating role in coagulation, with three different activation pathways. FXI deficiency is associated with bleeding under certain conditions. Low levels detected by activated partial thromboplastin time (APTT) methods (nonphysiological and dependent on contact activation via factor XII) do not necessarily predict bleeding. ${ }^{1}$ The APTT does indeed not reflect clinically relevant FXI function as it measures the initiation of coagulation and not the amount or solidity of clot formation. Following tissue injury, tissue factor (TF) VII is activated, which in turn leads to FXI activation by thrombin. This results in feedback enhancement of the TF-independent pathway via FIX. Polyphosphates released from platelets enhance FXI activation considerably. ${ }^{2}$ Global coagulation tests can now help to understand this mechanism further. Thrombin generation testing (TGT) can predict the bleeding tendency when measured in platelet-rich plasma (when contact activation is inhibited). ${ }^{3}$ The TGT is however not easily automated and not generally available for patient assessment. In this issue of Thrombosis and Haemostasis, Calderara and colleagues described a novel method of coagulation assessment, called thrombodynamics. ${ }^{4}$ They provided a three-dimensional measure of coagulation, based on clot development after the initial thrombin burst (which is the time point measured by the APTT). In this assay, TF was fixed on the surface to trigger coagulation, but the subsequent three-dimensional trace was TF-independent and reflected action of the FXI feedback loop on the rate of
Address for correspondence Paula H.B. Bolton-Maggs, Faculty of Biology, Medicine and Health, University of Manchester, Oxford Road, Manchester M13 9PL, United Kingdom

(e-mail: paula.bolton-maggs@manchester.ac.uk).

clot growth and size. This method could also discriminate between patients with or without a bleeding history, although only a small number of patients were studied. Further evidence is required, but development of global assays is beginning to assist prediction of bleeding risk in FXI-deficient patients. It is important to decide carefully who requires replacement therapy since treatment with FXI concentrate is associated with an increased risk of thrombosis.

Conflict of Interest

None declared.

\section{References}

1 Bolton-Maggs PH. Factor XI deficiency-resolving the enigma? Hematology Am Soc Hematol Educ Program 2009;2009(01): 97-105

2 Wheeler AP, Gailani D. Why factor XI deficiency is a clinical concern. Expert Rev Hematol 2016;9(07):629-637

3 Pike GN, Cumming AM, Hay CR, Bolton-Maggs PH, Burthem J. Sample conditions determine the ability of thrombin generation parameters to identify bleeding phenotype in FXI deficiency. Blood 2015;126(03):397-405

4 Bertaggia Calderara D, Zermatten MG, Aliotta A, Batista Mesquita Sauvage AP, Carle V, Heinis C, Alberio L. Tissue factor-independent coagulation correlates with clinical phenotype in factor XI deficiency and replacement therapy. Thromb Haemost 2020;120(02): 150-163

\section{received}

September 9, 2020

accepted

September 10, 2020

published online

October 29, 2020 (c) 2020. Thieme. All rights reserved. Georg Thieme Verlag KG,

Rüdigerstraße 14,

70469 Stuttgart, Germany
DOI https://doi.org/

$10.1055 / \mathrm{s}-0040-1718731$ ISSN 0340-6245. 